\title{
A review on humanoid robots
}

Rabbia Mahum*, Faisal Shafique Butt, Kashif Ayyub, Seema Islam, Marriam Nawaz, Daud Abdullah

Department of Computer Science, COMSATS Institute of Information Technology, Wah Cantt, Pakistan

\section{A R T I C L E IN F O}

\section{Article history:}

Received 23 November 2016

Received in revised form

7 February 2017

Accepted 7 February 2017

\section{Keywords:}

Humanoid robots

Behaviour

\section{Introduction}

Humanoid robotics is the field which is increasing in popularity day by day. Many groups are working on some issues like interacting, learning and controlling for applying them in human robotics.

These works forced the human to create a tool like humans which can work in the places where we want them, as human can work. Human body is designed by nature to work in each environment like stairs, doors, handles etc., so the basic centred structure is a base to build humanoid robots. If newly built humanoid robots can give gestures like moving eye/head, can analyze language, then it can do communication with other humans or agents.

As human can think about situation in many ways and solve the problems in routine to obtain the satisfactory results. In this paper, deep discussion of humanoid robots is the basic topic that how they act in real world environment like humans including different examples. Human robots are described as "mechanical knight" by Leonardo in 1495 A.D. (Gates, 2008). Robots are not only those devices which follow humans but they can be the leader in the game. Humanoid robots can participate in games as humans or they can work like humans having human like structure. To build humanoid robots some methodologies are used, one of them is affordances. It determines relation between agent and specified environment using its sensing parts like grasper, eatable etc. in this methodology properties of world and objects are included in term

\footnotetext{
* Corresponding Author.

Email Address: mbiya4965@gmail.com (R. Mahum) https://doi.org/10.21833/ijaas.2017.02.015

2313-626X/C 2017 The Authors. Published by IASE. This is an open access article under the CC BY-NC-ND license (http://creativecommons.org/licenses/by-nc-nd/4.0/)
}

of operations which the robot able to do. They are used to define the effects of operations performed and actions to achieve the specific goal.

In neuroscience field researchers are interested to introduce artificial intelligence in robots. RobotCub project while designing humanoid robots, is also a very important to interact with environment (Tsagarakis et al., 2007). The basic purpose is to behave like a child age of 1.5 to 2.5 years old in similar manner. In this strategy robots are made and by placing them in environment where they learn from interactions with people and objects. In the result the robot was built which was $100 \mathrm{~cm}$ in height, having the shape like a child, weighs approximately $23 \mathrm{~kg}$ and 53 of degrees of freedom (DOF). Because of this DOF they have less freedom of moving hands and their body than a child.

Social robots are used in different games by interacting with other participants in games to motivate them and giving them cues that how they will act next. In human to human interaction body movement is very important to judge the coordination in joint activities. Social robots exhibit meaningful interaction with their users (Jung and Lee, 2004). It is not necessary that they have the body form like humans they can be a toys or the instructor for education etc. (Fong et al., 2003). But two experiments were made by Lee et al. (2006) showed that whether the physical body of social robots is more effective or not. He found that in human-robot interaction it really matters that the robot should be physically like human, although the social robots not necessarily provide physical functionality. Also in an empirical study people got high scores in negotiation game when they interact with humanoid robot than computer screen.

Different strategies are used for interaction of humanoid robots with humans; tactile sensing is 
under discussion in the paper. Tactile sensing is very useful and safe during interaction while in unmannered environment.

Last but not the least humanoid robots are built to understand the intelligence of humans and act accordingly. The aim of this work is to describe the aspects of building humanoid robots within artificial intelligence, sensing strategies, software system, architecture and etc. which are used to sense the environment (i.e. the basic part of humanoid robots).

\subsection{History}

Idea for the humanoid robots is not new. Alexander made the robots like human which were animated with the help of liquid. After that Leonardo in 1495 developed a robot which could move his mouth and move its arms and neck. When $18^{\text {th }}$ century passing, robots were made, which were musicians or could write sentences etc.

After this many researchers and corporations developed their humanoid robots which could speak, walk, run etc. The starting of humanoid robots development based on Waseda University, Tokyo. The robots which was developed by them is Wabot1 , it was just like human, could walk, played music, held the objects, spoke in Japanese etc.

\section{Literature review}

Recently the field of generation of robots from industrial side to human friendly robots have been increased, which are able to interact like in hospitals, offices, homes etc. study of humanoid robotics is more relevant because of anthropomorphism, friendly design, locomotion and behaviour with human living environment etc. Usually it is preferable to build small size robots because they are less harmful for people and easy to control. When robots grasp any object then the physical characteristics are changed e.g. momentum depending upon the object. So in humanoid robots the learning method is also introduced. A modular control approach was described in which two models were used, a forward which tells the next state from present state on the other side the inverse model tells motor command from both states i.e. predicted and present. This motor prediction differentiates self-generated movements with external disturbances.

Classic robots are used where interaction is take place at specified places so force or torque sensors are used maximally. But in modern humanoid robots as interaction is not take place at pre specified places and they also have arms and legs grasping something and controlling so they use skin-like sensors for safe interactions. As in modern robots not only hands and legs interact with environment but also the complete body of humanoid robots have to interact with the environment, is largely under consideration now a days (Ohmura and Kuniyoshi, 2007). Although there are advantages of this strategy but there are also some drawbacks like its distributed nature or big size touch element sensors cause them to be fragile. When designing them they were found less important because of no system approach (Dahiya et al., 2008).

Some researchers said that physical embodiment has a positive effect during the interaction of humanoid robots and humans. Social humanoid robots require set of skills so that they can encourage the user during the interaction. For this one example of drumming humanoid robots is observed under this study. Drum-mate is an interactive game in which the robot KASPAR (kinesics and synchronization in personal assistant robotics) play drums with the human partner, matching the rhythm with human. This robots move head and give eye blinked gestures while drumming. In the result users were more encouraged in game due to gestures. After this similar experiment was done with 66 primary school students and same results were obtained.

One example of the humanoid robot is iCub which have head, torso, arms and legs. As it is used for children so legs are used for crawling only. For this purpose it is needed to explore environment thorough locomotion. For this they are equipped with enough degrees of freedom so that they can identify the objects lying in the environment or on floor. The upper part of the robot has the system for visual perception and hands are equipped with tactile sensing to manipulate the objects. Hands are built in such a way so that to save space and also cost by reducing power consumption. Whole robot is built with rigid mechanical coupling.

All organisms move their eyes to focus on specific place and then take input to head sensory systems. It is a part that supports the processing information (Lungarella and Sporns, 2006; Pfeifer et al., 2007). Audio modality is also added to humanoid robots to visualized data, and is used for face recognition. For the first time when humanoid robots interact then the interaction history is also saved in database. Then history is divided into the sensor motor coupling of robot and the action capabilities also depend on this history. The history actions can be selected and deleted and these actions are basis for the ontogenetic development for the humanoid robots. And also these organizing operations give abstraction and anticipation as well (Mirza et al., 2008). To store data in interaction history firstly humanoid robots have to sense the objects or environment. For this purpose tactile sensors are usually used. According to Hoshi and Shinoda (2006) gave the concept of making tactile sensors having small structure of wireless transducer distributed randomly in mould silicone rubber and needs a link of communication and power supply. But it was not so feasible so other ideas were given which consume less power.

One example of skin system for humanoid robot is by Taichi et al. (2006) in which sensors detect stimuli from the users who want to interact with the robot. It has low spatial resolution (area is 
approximately $25 \mathrm{~cm}^{2}$ ), having the limitation of measuring frequency from $10-15 \mathrm{~Hz}$.

The contribution of this paper is to determine all the basic methodologies and techniques which are contribute to form humanoid robots with artificial intelligence. Other than this the architecture of humanoid robots and the software are also discussed. Some examples of humanoid robots are taken to explain the sensing parts in humanoid robots.

\section{Characteristics}

\subsection{Bipedal Locomotion}

For humanoid robots it is unique feature. For humans to walk and move is very easy but for humanoid robots it is difficult. There are two approaches for this purpose which are opposing. One is zero moment point theory according to which there is a point on the floor around which the sum of moment of all the forces is equal to zero. If this point is under the convex hull of all relative places between the legs and ground, then the robot is erect in dynamic way. Another approach centre of mass projection, defines the stability of robot statically. Robots like Sony Qrio. And Honda Asimo based on ZMP-based control was capable of $6 \mathrm{~km}$ per hour running. But gait due to bended knees does not resemble humans. Although energy stored in elastic elements is not recycled just like humans so it is said that it is not efficient to preserve energy. Moreover Asimo needs flat floor to walk and run, can climb some stairs.

Another technique to walk is to use the robot's dynamics. McGeer (1990) gave idea that planar walking through a slope place can be with no actuators and control. Using this idea actuated machines or systems are built (Collins et al., 2005). They can walk through flat floor. Their parts give support to systems; because of this they are better. They can be handling easily and controllable due to sensors of foot contact. Due to feet shape they cannot stand constantly. One other drawback is they cannot start to walk or pause voluntarily and also are not capable changing of way.

In recent humanoid robots the basic property missing is walking through steep path. These properties are determined by the quadruped (Kim et al., 2007).The humanoids were not suitable for usage in house because of combusting machinery and parts. It was difficult to simulate these properties due to less workable actuators. But hydraulic actuators and pneumatic actuators are used to implement joint's parts but they cannot walk better.

\subsection{Perception}

Robotics should follow the condition and perceive the surroundings to achieve the goal. Due to perception, robots check their state of joints by using encoders or sensors. Accelerometers and gyroscopes are also used for estimating the attitude of robots. Robots like $\mathrm{CB}^{2}$, developed at Osaka University, are covered with force-sensitive skins. Many humanoid robots use senses like laser rangefinders or ultrasonic distance sensors, and most important properties for them are their vision and audition power. Humanoid robots use cameras, to active seeing power allowing them to focus their attention towards specific objects. Robots are also having some screens to interpret the images.

Similarly when robots have to identify the audio signals, difficulties arise. The basic problem is to separation of sound of user with the other noise in the environment. So turning the microphones towards user and beaming the microphones make easier to hear user. But this approach only improves the signal to noise ratio, still noise interpretation is difficult. Many robots like voice recognizing machines have the problem rates.

Because of above problems in perceiving, robots take signals and then those signals are captured and interpreted by humans (e.g. example Geminoid (Nishio et al., 2007) by Ishiguro and the Robonaut (Ambrose et al., 2004) by NASA).

\subsection{Interaction}

Humanoid robots are built to use in place of humans or with other humans. Here the basic idea is that the techniques which are used in human-human interaction, they can be used as an initiative for human-robot interaction. These properties are available by birth in humans but to build these modalities in humanoid robots, they should be equipped with expressive animated heads. For example WE-4RII developed at Waseda (Miwa et al., 2004). When humanoid robots look at the opposing user, then user understand that robot is interacting with him. Many of humanoids also move lips part when saying something. Same in humans, animating mouth make easy for user to identify the voice. Many of humanoids can give the facial expressions through movement of eyelids, lips etc.

Other than face expressions, humanoid robots having anthropomorphic hands and arms use to make gestures. Minimum 4 joints are there in one arm for example the hands in Joy (Kim et al., 2007). Movements which are usually generated by humanoid robots are symbolic gestures like welcome to people. Measurement of things can be representing through hands. Humanoid robots with full body use their complete parts for interaction. For example, HRP-2 which dances by seeing the human Japanese dance (Nakaoka et al., 2006). Children who have disorders in their development, for them keepon (Kozima et al., 2009) robots were created as given in Fig. 1. Children of more than three years old were allowed to interact with them for one hour and the results shows that they approach the robot and establish social contact with them spontaneously. QRIO (Tanaka et al., 2007) were developed for children of different age groups for interaction as 
given in Fig. 2. These robots were able to do different dance movements and mimicking steps.

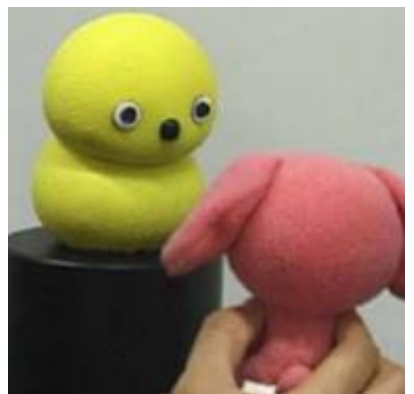

Fig. 1: Keepon (Kozima et al., 2009)

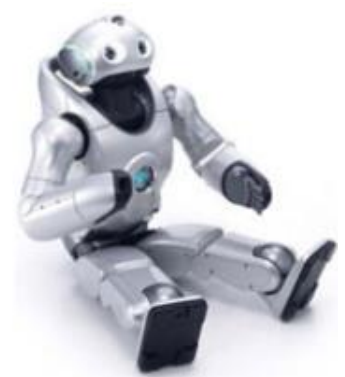

Fig. 2: QRIO (Tanaka et al., 2007)

\subsubsection{Interaction history}

Humanoid robots which use interaction history, they then select their next action on the basis of history. Interaction history consists of four basic parts. First is the values which are taken from the sensors during the interaction, it includes all the sensors. Second part is measurement of the gap between the interaction series. Third part is checking the association of next action. Fourth part is the value obtained for the quality of environment.

\subsubsection{Action selection}

Humanoid robots have the ability to perform actions more than one simultaneously. The action performed by the robot can be selected without any sequence or it can be selected on the basis of past recent actions in the history. As the humanoid robots have the ability to choose action without any sequence so it can be possible that it can perform better or new actions during interaction. In start robots select actions randomly but after that they started to select actions from past experiences. It provides the association in behaviour of the robots.

\subsubsection{Example}

Here is the example in which human is playing game peekaboo and humanoid robots use its history of interaction. Player and the machine were placed in front of each other. Firstly the machine has empty interaction history. Then the game starts and human machine system perform different actions. This interaction takes two to three minutes.

Three different criteria were tried first is that peekaboo encouraged, second is encouragement of alternative sequences of actions and third is no encouragement. When results were computed, total 22 runs from which 16 were for first condition, 3 for second and also 3 for third condition. The conclusion of this game was that by encouraging robot as it performs series of actions provide results in those actions which are selected in preference from others in same environment.

\subsection{Dexterous manipulation}

Humans have the ability to move their hands almost 30 DOF. In modern humanoid robots shadow arms, made through forty air muscles (Behnke, 2008). This property needs also collaboration of arms and also the visual machinery. If there are many joints then to control them is also difficult.

Some of the humanoid robots were built which cannot hold the unknown objects from the environment like humans. The reason behind this is lack of learning ability to perceive and sensing the new objects. Improvements were needed so that they could hold the things and sense them by touching.

\subsection{Learning behaviour}

Whenever humanoid robots interact with environment, the interaction would be unpredictable. So they should learn new concepts from the environment with which they are interacting. Actually they have the ability that they

can learn from the users or people present in the surroundings, i.e. imitating the concepts (Schaal, 1999) or program through logics (Cypher and Halbert, 1993). For this type of learning, gestures have been made like moving tennis in air (Calinon and Billard, 2007) and for other difficult movements. Challenge is to perceive the teaching person and other challenge is transferring the movements of person to humanoid robots. For first one there are sensors which sense the motion of person. But for other one there are limitations in movements of humanoid robots because of lack of flexibility. But DOF is used to avoid this. One solution may be that person should move the joints of robots by them but it is not acceptable. So for correct learning the robot should learn itself by using different possibilities.

Optimizing the learning process is a great success in humanoid robots, for this one of the technique is reinforce the robot (Sutton and Barto, 1998). But one issue is that how to increase the positive results by reducing punishments of robots, when it interact with the environment. For this the best approach is stochastic approach, in its walk ability is better (Faber and Behnke, 2007), also learn ability naturally is increased (Peters and Schaal, 2008). We don't suppose that the surroundings itself produce the best environment during the learning difficult tasks. But middle rewards should be produced through humanoid robots while completing small tasks. Although they should produce opposite rewards also while opposing the limitations, e.g. fall 
of robot. The best property for learning humanoid robots should pick the new concepts from the environment. Because it is not necessary that the environment is constant, as humans do their work in every environment like in rain, or in sunny atmosphere. So humanoid robots should identify the new concepts for example in instructor robots, they should be capable of recognizing new words from students. Some of humanoid robots have the ability that they make the view of their environments (e.g. Gutmann et al. (2005) used Sony Qrio).

\subsection{Sensing behaviour}

There are different types of sensors used in humanoid robots. But we are focusing on specific on sensors used to grasp the objects means arm's sensors. Sometimes arms are small so according to them, sensors must be small according to the joints. For loop gesture of hand, there should be a measurement of every joint. Many approaches are used for this but Butterfass et al. (2001) gave concept of using plastic potentiometer at ever finger's joints. Another technique by Chua et al. (2006) gave that linear potentiometers at wrist joint to calculate the angles of joints. But this idea was flopped due to lack of precision cause of friction of tendons. Most useful idea was given by Behnke (2008).

\section{Applications}

Due to limitations of humanoid robots, they cannot behave just like human beings. But we have application domains in routines, in which they are used. Some of them are discussed here.

\subsection{ICub robot}

This is a robot made for child age of 1.5 years to 2.5 years. It involves the child in games and does crawling like child. But also have some limitation in hands movement, which can't move as child's hands as described in Fig. 3.

\subsection{Technology}

Popular robotics Honda Asimo (Chestnutt et al., 2007) and Toyota Partner Robots (Ichijo and Kohlbacher, 2008) actually cannot provide specific functionality. But they are used for the marketing purposes like climbing on stairs, playing drums etc. to introduce the new technologies and to attract the audience. Although they are expensive but can compensate through the technology marketing.

\subsection{Space purpose}

One other application which is not expensive but as we know, for research purposes it may be harmful for a person to go on space and then find answers of questions. So it is acceptable that send the humanoid robots on space. By making humanoid robots it is admirable here because they can use tools which are made for humans to go on space. One of the examples is Robonaut shown in Fig. 4.
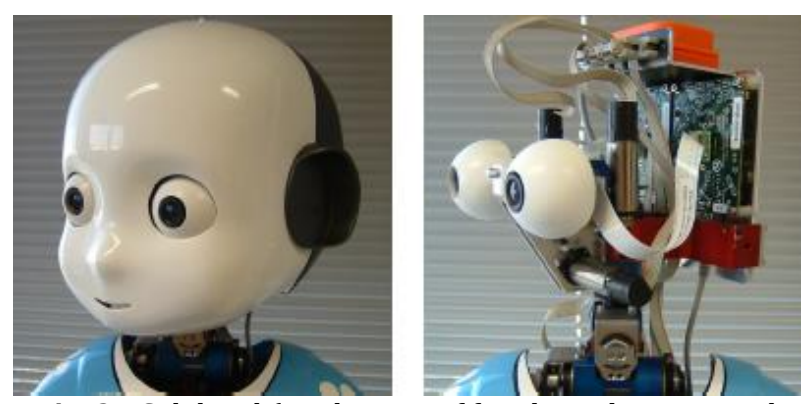

Fig. 3: ICub head (six degrees of freedom tilt, swing and pan for the neck) (Ruesch et al., 2008)

\subsection{Manufacturing purpose}

In industries robots are also used due to two arms like humans. When Japan's company named Yaskawa got introduced by two armed robots, said that Motoman-SDA10 (Behnke, 2008), which have 2 seven DOF. and rounded joints shown in Fig. 5. One arm is capable of ten kilogram lifting. That manufacturing humanoid robots can grasp thing in one hand during use of other hand, handling the equipment. It is said that in china the cost of them is less than the human resource in production.

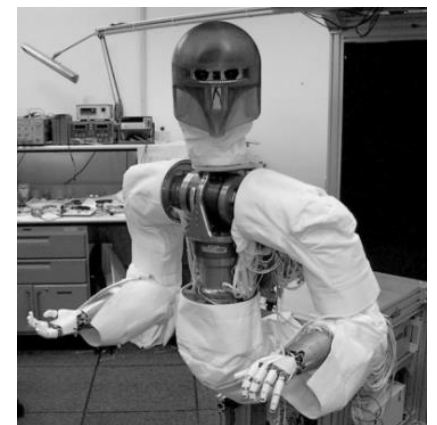

Fig. 4: Robonaut (Bluethmann et al., 2003)

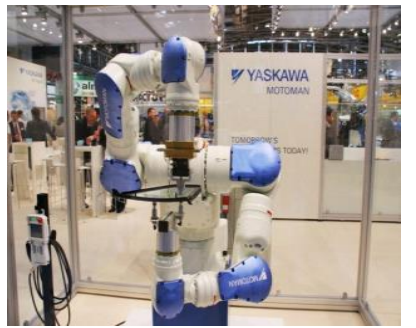

Fig. 5: Motoman-SDA (Behnke, 2008)

\subsection{Household}

One of the household examples is vacuum cleaner robot. Armar robots are for household purposes shown in Fig. 6 (Asfour et al., 2006). These robots have the specific skills which are required in houses e.g. waiter robots. For example they can copy the human being and can understand the instructions given by them. It can get things out from refrigerator and can break eggs etc. 


\subsection{Competition's robots}

One of the important applications is using robots in different competitions. They may be competitors in a game or like RoboCup and FIRA. These are robots, which play as an opposite groups. If these are fallen, they get up on their own and again play. These types of robots provide the basis for the artificial intelligence. Humanoid robots are also used in battles as military purposes, the life of human beings is more important than robots (Table 1 and Table 2).

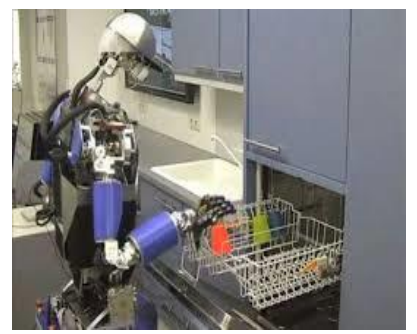

Fig. 6: Armar robots (Asfour et al., 2006)

\section{Conclusion}

The requirements of human beings are increasing day by day as humanoid robots serve the human in many fields. For example in production or manufacturing it is estimated that the cost of human resource is more than on humanoid robots, in china. But the one problem in humanoid robots is during perception and voice interpretation. Although as time passing, researchers are introducing new strategies to cope with this difficulty. Not only in software side but improvements in physical structure are also needed. Researchers are developing flexible actuators like muscles. Research in the field of artificial intelligence humanoid robots is very much convincing, but still there is a lot to learn in field of perception, interpretation and controlling. There is a big challenge of complexity of system and cost, which can make hurdle for humanoid robots developers. But the big step is made by the toy's industries which introduce the less costly humanoid robots for children.

Table 1: Summary of Applications of different robots

\begin{tabular}{|c|c|c|c|c|}
\hline Robot & Capabilities & Design & $\begin{array}{l}\text { Num. of } \\
\text { Session }\end{array}$ & Results \\
\hline $\begin{array}{l}\text { Robovie } \\
\text { (Kanda et al., } \\
\text { 2004) }\end{array}$ & $\begin{array}{l}\text { Interact with users, } \\
\text { recognise them and } \\
\text { communicate in English }\end{array}$ & $\begin{array}{c}\text { Subjects: } 228 \text { Measures: range of } \\
\text { interaction, English communication } \\
\text { skills } \\
\text { Methods: video analysis, English } \\
\text { vocabulary tests } \\
\text { Subjects: } 8\end{array}$ & 9 days & $\begin{array}{l}\text { Interaction gradually reduced after } \\
\text { 1st week; betterment of English } \\
\text { communication skills of those } \\
\text { students who constantly took } \\
\text { sessions with robots }\end{array}$ \\
\hline $\begin{array}{l}\text { Wany (Salter } \\
\text { et al., 2004) }\end{array}$ & Hazards avoidance & $\begin{array}{l}\text { Measures: surroundings of the robots } \\
\text { Methods: video analysis, observation } \\
\text { of communicated data }\end{array}$ & 5 & $\begin{array}{c}\text { Students showed lack of interest in } \\
\text { later sessions. }\end{array}$ \\
\hline $\begin{array}{l}\text { QRIO } \\
\text { (Tanaka et } \\
\text { al., 2007) }\end{array}$ & $\begin{array}{l}\text { Choreography of dance } \\
\text { steps and intimating } \\
\text { movements of children }\end{array}$ & $\begin{array}{c}\text { Subjects: } 11 \\
\text { Measures: quality of communication } \\
\text { Methods: Analysis of video and its } \\
\text { observation }\end{array}$ & 15 & $\begin{array}{l}\text { The robot showed different care } \\
\text { taking behaviour towards toddlers }\end{array}$ \\
\hline $\begin{array}{l}\text { Keepon } \\
\text { (Kozima, et } \\
\text { al., 2009) }\end{array}$ & $\begin{array}{l}\text { Capable of showing non- } \\
\text { verbal expressions like } \\
\text { gaze, gestures and } \\
\text { emotions. }\end{array}$ & $\begin{array}{l}\text { Subjects: } 27 \\
\text { Measures: reactions of children } \\
\text { Methods: analysis of videos }\end{array}$ & 20 & $\begin{array}{c}\text { Robot takes the role of social peer; } \\
\text { children showed good response } \\
\text { over the sessions }\end{array}$ \\
\hline $\begin{array}{l}\text { iRobiQ } \\
\text { (Hyun et al., } \\
\text { 2010) }\end{array}$ & $\begin{array}{l}\text { Directing, building } \\
\quad \text { relationship }\end{array}$ & $\begin{array}{c}\text { Subjects: } 162 \text { Measures: intention of } \\
\text { use, curiosity, perceived knowledge, } \\
\text { IQ and adequacy of route guidance } \\
\text { Methods: questions }\end{array}$ & $\begin{array}{c}2 \text { to } 18 \\
\text { sessions }\end{array}$ & $\begin{array}{l}\text { Robot's suggestions of shopping } \\
\text { were accepted by observers }\end{array}$ \\
\hline $\begin{array}{l}\text { Roomba } \\
\text { (Sung et al., } \\
\text { 2009; Sung } \\
\text { et al., 2010) }\end{array}$ & $\begin{array}{l}\text { Vacuum cleaning, } \\
\text { Walk around the house }\end{array}$ & $\begin{array}{l}\text { Subjects: } 48 \text { (across } 30 \text { households) } \\
\text { Measures: robots acceptance } \\
\text { Methods: observation, surveys, } \\
\text { analysis, probing techniques ,cards } \\
\text {,questions }\end{array}$ & 6 months & $\begin{array}{l}\text { Many techniques should be } \\
\text { acclaimed to perceive people's } \\
\text { routines at home }\end{array}$ \\
\hline $\begin{array}{l}\text { Pleo } \\
\text { (Fernaeus et } \\
\text { al., 2010) }\end{array}$ & Animal-like behaviour & $\begin{array}{c}\text { Subjects: } 6 \text { families Measures: } \\
\text { exploratory study } \\
\text { Methods: surveys, video analysis and } \\
\text { pictures }\end{array}$ & 2-10 months & $\begin{array}{l}\text { Initial results of robot were not } \\
\text { satisfactory. After some time, } \\
\text { family members played with the } \\
\text { robot but only occasionally }\end{array}$ \\
\hline $\begin{array}{l}\text { Nabaztag } \\
\text { (Klamer et } \\
\text { al., 2010) }\end{array}$ & $\begin{array}{c}\text { health care } \\
\text { conversations; people } \\
\text { interact through yes- and } \\
\text { no-buttons }\end{array}$ & $\begin{array}{c}\text { Subjects: } 3 \text { (50-65 years, females) } \\
\text { Measures: acceptance of robots based } \\
\text { on performance } \\
\text { Methods: surveys }\end{array}$ & 10 days & $\begin{array}{l}\text { Usage and social factors are main } \\
\text { reasons to accept thesel robots in } \\
\text { domestic environments }\end{array}$ \\
\hline $\begin{array}{l}\text { PeopleBot } \\
\text { (Koay et al., } \\
\text { 2007) }\end{array}$ & $\begin{array}{l}\text { Approach the user in } \\
\text { several ways }\end{array}$ & $\begin{array}{l}\text { Subjects: } 12 \text { ( } 8 \text { male and } 4 \text { female) } \\
\text { Measures: economic preferences } \\
\text { Methods: surveys, questionnaire, } \\
\text { comfort device }\end{array}$ & $\begin{array}{l}8 \text { (aprox. } 1 \\
\text { hour each) }\end{array}$ & $\begin{array}{l}\text { User's preferences changed over } \\
\text { time }\end{array}$ \\
\hline
\end{tabular}

\section{Future work}

The field of artificial intelligence humanoid robots is very vast. People in past think that sometime there would be a robot, which can do some work according to program. And this is the time, when there are lots of humanoid robots which are used for many works. But characteristics of humanoid robots are still limited. This cannot be the solid reason to stop further research. Now a day's 
research on cognitive robotics is becoming popular.

Many researchers are going towards this.

Table 2: Summarize guidelines for future work (Leite et al., 2013)

\begin{tabular}{cc}
\hline Guidelines & Recommendations \\
Appearance & $\begin{array}{c}\text { Select embodiment depending upon the purpose of robots and its capabilities } \\
\text { Functional appearance should be well suited for home or office requirements } \\
\text { Animal-like embodiments cause lack of expectations of robot's social capabilities } \\
\text { Behaviours on daily basis (e.g., Well-wishing and Parties) }\end{array}$ \\
$\begin{array}{c}\text { Coherence } \\
\text { Emotional interactions and } \\
\text { sympathy } \\
\text { Memory and } \\
\text { differentiation }\end{array}$ & $\begin{array}{c}\text { Concerned behaviours (e.g., recollecting previous activities through history and self-exposure) } \\
\text { Increasing addition by learning new behaviours with time } \\
\text { Grasp the influencing state of people then response accordingly } \\
\text { Display and explore emotional reactions } \\
\text { Recognize current and old users }\end{array}$ \\
Remem ber details of previous interactions and recollecting them from history \\
Use data about that user to individualize the interaction
\end{tabular}

\section{References}

Ambrose RO, Savely RT, Goza SM, Strawser P, Diftler MA, Spain I, and Radford N (2004). Mobile manipulation using NASA's robonaut. In the IEEE International Conference on Robotics and Automation (ICRA '04), IEEE, New Orleans, USA, 2: 21042109. https://doi.org/10.1109/ROBOT.2004.1308134

Asfour T, Regenstein K, Azad P, Schroder J, Bierbaum A, Vahrenkamp N, and Dillmann R (2006). ARMAR-III: An integrated humanoid platform for sensory-motor control. In the 6th IEEE-RAS International Conference on Humanoid Robots, IEEE: 169-175. https://doi.org/10.1109/ICHR.2006. 321380

Behnke S (2008). Humanoid robots-from fiction to reality?. In the Künstliche Intelligenz Heft, 4, 5-9. Available online at: https://www.ais.uni-bonn.de/papers/KI08_Behnke.pdf

Bluethmann W, Ambrose R, Diftler M, Askew S, Huber E, Goza M, and Magruder D (2003). Robonaut: A robot designed to work with humans in space. Autonomous Robots, 14(2): 179-197.

Butterfass J, Grebenstein M, Liu H, and Hirzinger G (2001). DLRHand II: Next generation of a dextrous robot hand. In the IEEE International Conference on Robotics and Automation (ICRA), IEEE, Seoul, South Korea, 1: 109-114. https://doi.org/10. 1109/ROBOT.2001.932538

Calinon S and Billard A (2007). Incremental learning of gestures by imitation in a humanoid robot. In the $2^{\text {nd }}$ ACM/IEEE International Conference on Human-Robot Interaction (HRI), IEEE: 255-262. https://doi.org/10.1145/1228716.1228751

Chestnutt J, Michel P, Kuffner J, and Kanade T (2007). Locomotion among dynamic obstacles for the Honda Asimo. In the IEEE/RSJ International Conference on Intelligent Robots and Systems (IROS), IEEE, 2572-2573. https://doi.org/10.1109/ IROS.2007.4399431

Chua PY, Caldwell DG, Bezdicek M, Gray JO, and Davis S (2006). Tele-operated high speed anthropomorphic dextrous hands with object shape and texture identification. In the IEEE/RS] International Conference on Intelligent Robots and Systems, IEEE, Beijing, China: 4018-4023. https://doi.org/10.1109/ IROS.2006.281861

Collins S, Ruina A, Tedrake R, and Wisse M (2005). Efficient bipedal robots based on passive-dynamic walkers. Science, 307(5712): 1082-1085.

Cypher A and Halbert DC (1993). Watch what I do: programming by demonstration, MIT press, Cambridge, UK.

Dahiya RS, Valle M, and Metta G (2008). System approach: A paradigm for robotic tactile sensing. In the $10^{\text {th }}$ IEEE International Workshop on Advanced Motion Control (AMC '08), IEEE: 110-115. https://doi.org/10.1109/AMC.2008. 4516050

Faber F and Behnke S (2007). Stochastic optimization of bipedal walking using gyro feedback and phase resetting. In the $7^{\text {th }}$ IEEE-RAS International Conference on Humanoid Robots, IEEE: 203-209. https://doi.org/10.1109/ICHR.2007.4813869
Fernaeus Y, Håkansson M, Jacobsson M, and Ljungblad S (2010). How do you play with a robotic toy animal? a long-term study of Pleo. In the $9^{\text {th }}$ International Conference on Interaction Design and Children (IDC '10), ACM, Barcelona, Spain: 39-48. https://doi.org/10.1145/1810543.1810549

Fong T, Nourbakhsh I, and Dautenhahn K (2003). A survey of socially interactive robots. Robotics and Autonomous Systems, 42(3): 143-166.

Gates B (2008). A robot in every home. Scientific American, 18(1): 4-11.

Gutmann JS, Fukuchi M, and Fujita M (2005). A floor and obstacle height map for 3D navigation of a humanoid robot. In the IEEE International Conference on Robotics and Automation (ICRA), IEEE, Barcelona, Spain: 1066-1071. https://doi.org/10.1109/ ROBOT.2005.1570257

Hoshi T and Shinoda H (2006). Robot skin based on touch-areasensitive tactile element. In the IEEE International Conference on Robotics and Automation (ICRA), IEEE, Orlando, USA: 3463-3468. https://doi.org/10.1109/ROBOT.2006.1642231

Hyun E, Yoon H, and Son S (2010). Relationships between user experiences and children's perceptions of the education robot. In the 5th ACM/IEEE International Conference on HumanRobot Interaction (HRI), IEEE, Osaka, Japan: 199-200. https://doi.org/10.1109/HRI.2010.5453197

Ichijo K and Kohlbacher F (2008). Tapping tacit local knowledge in emerging markets-the Toyota way. Knowledge Management Research and Practice, 6(3): 173-186.

Jung Y and Lee KM (2004). Effects of physical embodiment on social presence of social robots. In the $7^{\text {th }}$ Annual International Workshop on PRESENCE, Valencia, Spain: 80-87.

Kanda T, Hirano T, Eaton D, and Ishiguro H (2004). Interactive robots as social partners and peer tutors for children: A field trial. Human-Computer Interaction, 19(1): 61-84.

Kim HH, Lee HE, Kim YH, Park KH, and Bien ZZ (2007). Automatic generation of conversational robot gestures for humanfriendly steward robot. In the $16^{\text {th }}$ IEEE International Symposium on Robot and Human interactive Communication (RO-MAN), IEEE, Jeju, South Korea: 1155-1160. https:// doi.org/10.1109/ROMAN.2007.4415254

Klamer T, Allouch SB, and Heylen D (2010). "Adventures of Harvey"-Use, acceptance of and relationship building with a social robot in a domestic environment. In the International Conference on Human-Robot Personal Relationship, Springer Berlin Heidelberg: 74-82. https://www.doi.org/10.1007/9783-642-19385-9_10

Koay KL, Syrdal DS, Walters ML, and Dautenhahn K (2007). Living with robots: Investigating the habituation effect in participants' preferences during a longitudinal human-robot interaction study. In the $16^{\text {th }}$ IEEE International Symposium on Robot and Human interactive Communication (RO-MAN), IEEE, Jeju, South Korea: 564-569. https://doi.org/10.1109 /ROMAN.2007.4415149

Kozima H, Michalowski MP, and Nakagawa C (2009). Keepon. International Journal of Social Robotics, 1(1): 3-18. 
Lee KM, Jung Y, Kim J, and Kim SR (2006). Are physically embodied social agents better than disembodied social agents? The effects of physical embodiment, tactile interaction, and people's loneliness in human-robot interaction. International Journal of Human-Computer Studies, 64(10): 962-973.

Leite I, Martinho C, and Paiva A (2013). Social robots for longterm interaction: a survey. International Journal of Social Robotics, 5(2): 291-308.

Lungarella M and Sporns O (2006). Mapping information flow in sensorimotor networks. PLoS Computational Biology, 2(10): e144. https://doi.org/10.1371/journal.pcbi.0020144

McGeer T (1990). Passive dynamic walking. The International journal of Robotics Research, 9(2): 62-82.

Mirza NA, Nehaniv CL, Dautenhahn K, and Te Boekhorst R (2008). Anticipating future experience using grounded sensorimotor informational relationships. In the Artificial Life XI: Proceedings of the Eleventh International Conference on the Simulation and Synthesis of Living Systems, MIT Press, Cambridge, UK.

Miwa H, Itoh K, Matsumoto M, Zecca M, Takanobu H, Rocella S, and Takanishi A (2004). Effective emotional expressions with expression humanoid robot WE-4RII: integration of humanoid robot hand rch-1. In the IEEE/RSJ International Conference on Intelligent Robots and Systems (IROS '04), IEEE, Sendai, Japan 3: 2203-2208. https://doi.org/10.1109/IROS.2004.1389736

Nakaoka S, Nakazawa A, Kanehiro F, Kaneko K, Morisawa M, Hirukawa H, and Ikeuchi K (2006). Leg task models for reproducing human dance motions on biped humanoid robots. Journal of the Robotics Society of Japan, 24(3): 388399.

Nishio S, Ishiguro H, and Hagita N (2007). Geminoid: Teleoperated android of an existing person. INTECH Open Access Publisher, Vienna, Austria.

Ohmura Y and Kuniyoshi Y (2007). Humanoid robot which can lift a $30 \mathrm{~kg}$ box by whole body contact and tactile feedback. In the IEEE/RSJ International Conference on Intelligent Robots and Systems (IROS), IEEE: 1136-1141. https://doi.org/10.1109/ IROS.2007.4399592

Peters J and Schaal S (2008). Natural actor-critic. Neurocomputing, 71(7): 1180-1190.
Pfeifer R, Lungarella M, Sporns O, and Kuniyoshi Y (2007). On the information theoretic implications of embodiment-principles and methods. In 50 years of artificial intelligence. Springer Berlin Heidelberg, Germany.

Ruesch J, Lopes M, Bernardino A, Hornstein J, Santos-Victor J, and Pfeifer R (2008). Multimodal saliency-based bottom-up attention a framework for the humanoid robot iCub. In the IEEE International Conference on Robotics and Automation (ICRA), IEEE: 962-967. https://doi.org/10.1109/ROBOT. 2008.4543329

Salter T, Dautenhahn K, and Bockhorst R (2004). Robots moving out of the laboratory-detecting interaction levels and human contact in noisy school environments. In the $13^{\text {th }}$ IEEE International Workshop on Robot and Human Interactive Communication (ROMAN), IEEE, Kurashiki, Japan: 563-568. https://doi.org/10.1109/ROMAN.2004.1374822

Schaal S (1999). Is imitation learning the route to humanoid robots?. Trends in Cognitive Sciences, 3(6): 233-242.

Sung J, Christensen HI, and Grinter RE (2009). Robots in the wild: understanding long-term use. In the 4th ACM/IEEE International Conference on Human-Robot Interaction (HRI), IEEE, La Jolla, USA: 45-52.

Sung J, Grinter RE, and Christensen HI (2010). Domestic robot ecology. International Journal of Social Robotics, 2(4): 417429.

Sutton RS and Barto AG (1998). Introduction to reinforcement learning. MIT Press, Cambridge, UK.

Taichi T, Takahiro M, Hiroshi I, and Norihiro H (2006). Automatic categorization of haptic interactions-what are the typical haptic interactions between a human and a robot?. In the $6^{\text {th }}$ IEEE-RAS International Conference on Humanoid Robots, IEEE: 490-496. https://doi.org/10.1109/ICHR.2006.321318

Tanaka F, Cicourel A, and Movellan JR (2007). Socialization between toddlers and robots at an early childhood education center. Proceedings of the National Academy of Sciences, 104(46): 17954-17958.

Tsagarakis NG, Metta G, Sandini G, Vernon D, Beira R, Becchi F, and Caldwell DG (2007). iCub: the design and realization of an open humanoid platform for cognitive and neuroscience research. Advanced Robotics, 21(10): 1151-1175. 